\title{
Long-term postoperative satisfaction and complications in nasal bone fracture patients according to fracture type, site, and severity
}

\author{
Min Hyub Choi, \\ Ji Seon Cheon, \\ Kyung Min Son, \\ Woo Young Choi \\ Department of Plastic and \\ Reconstructive Surgery, Chosun \\ University College of Medicine, \\ Gwangju, Korea
}

\begin{abstract}
Background: It is difficult to completely fix nasal bone fractures with closed reduction, as it is often accompanied by septal cartilage damage, and this often results in postoperative secondary deformities. Thus, patients are often reluctant to undergo closed reduction surgery. The present study aimed to evaluate aesthetic and functional satisfaction, as well as satisfaction with and complications of closed reduction, according to nasal bone fracture type.

Methods: The subjects were patients who underwent closed reduction under general anesthesia from January 2017 to December 2018. Based on the modified Murray classification, patients were classified into five groups according to the fracture site, septal fracture, and deviation. A total of 211 patients were sent a web-based survey on postoperative satisfaction and complications, as well as intention for revision and cosmetic surgery. Sixty-one patients $(28.9 \%)$ responded.

Results: There were no significant differences in aesthetic and functional satisfaction or satisfaction with closed reduction according to the fracture type, site, or severity. Postoperative functional complications developed in 14 of 61 patients (22.95\%). With 10 out of $24(41.67 \%)$ patients $(p=0.044)$, the bilateral fracture with septal fracture or prominent septal deviation type had a higher incidence of complications than the other types.

Conclusion: The incidence of complications is higher for bilateral fracture with septal fracture or prominent septal deviation compared to the other nasal bone fracture types. Therefore, long-term follow-up after closed reduction surgery for this fracture type can aid in establishing additional postoperative treatment plans and improving patient satisfaction.
\end{abstract}

Keywords: Bone fractures / Closed fracture reduction / Esthetics / Nasal bone / Postoperative complications

\section{INTRODUCTION}

The nasal bone, which protrudes at the center of the face, is one of the most commonly fractured facial bones as a result of trauma [1].

\section{Correspondence: Ji Seon Cheon}

Department of Plastic and Reconstructive Surgery, Chosun University College of

Medicine, 365 Pilmun-daero, Dong-gu, Gwangju 61453, Korea

E-mail: ps9107@naver.com

This work was supported by Chosun University Research Fund.

Received October 26, 2019 / Revised November 16, 2019 / Accepted November 22, 2019
Surgical treatments for nasal bone fracture include closed reduction, open reduction, and rhinoplasty, of which closed reduction is the standard treatment because it allows a safe, simple, and effective reduction [1-3]. However, it is difficult to completely fix nasal bone fractures using closed reduction, as it is frequently accompanied by septal cartilage damage and often leads to postoperative secondary deformities; therefore, patients are reluctant to undergo treatment using this surgical method [2-6]. Previous studies have looked at various approaches to improve patient 
satisfaction after closed reduction of nasal bone fractures; however, these studies do not differentiate between aesthetic satisfaction and functional satisfaction, and they do not assess longterm ( $>6$ months) satisfaction [7-9].

The present study aimed to evaluate aesthetic and functional satisfaction in patients with nasal bone fracture who underwent closed reduction. The evaluation was carried out taking various factors into account, such as the type, site, and severity of the fracture. In addition, we aimed to investigate the long-term prognosis of patients after closed reduction of nasal bone fracture by comparison of complications and intention for revision.

\section{METHODS}

\section{Patients}

Patients who underwent closed reduction of nasal bone fracture performed by three operators (JSC, KMS, and WYC) under general anesthesia between January 2017 and December 2018 were enrolled. Patients who underwent surgery under local anesthesia or had a concomitant facial bone fracture were excluded from the study. Demographic information such as sex, age, and mechanism of injury was collected through medical records. The study was approved by the Institutional Review Board of Chosun University Hospital (IRB No. 2019-09-004-002).

\section{Patient classification}

To classify patients by fracture type, the following criteria were applied through modification of the Murray classification (Fig. 1) $[10,11]:$ Am, unilateral fracture without septal fracture or prominent septal deviation; As, unilateral fracture with septal fracture or prominent septal deviation; Bm, bilateral fracture without septal fracture or prominent septal deviation; Bs, bilateral fracture with septal fracture or prominent septal deviation; C, comminuted fracture.
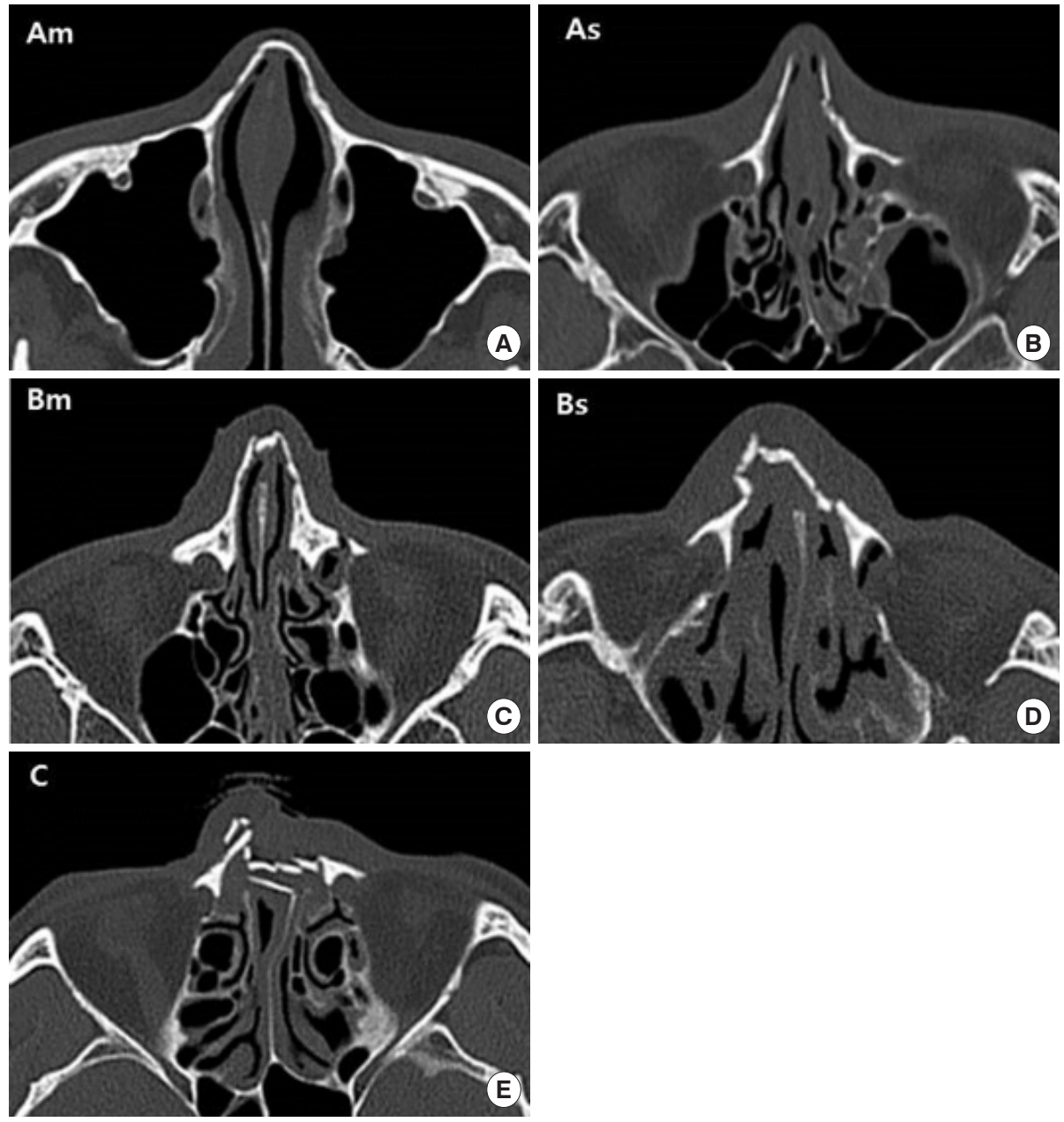

Fig. 1. Patient classification. (A) Am, unilateral fracture without septal fracture or prominent septal deviation. (B) As, unilateral fracture with septal fracture or prominent septal deviation. (C) Bm, bilateral fracture without septal fracture or prominent septal deviation. (D) Bs, bilateral fracture with septal fracture or prominent septal deviation. (E) C, comminuted fracture. 
A trained assistant (MHC) classified a total of 211 patients based on both preoperative computed tomography images and preoperative photos, resulting in 31 patients (14.6\%) in the Am group, 58 patients (27.5\%) in the As group, 20 patients (9.5\%) in the Bm group, 75 patients (35.5\%) in the Bs group, and 27 patients (12.8\%) in the C group.

\section{Satisfaction and complication questionnaire}

To evaluate postoperative satisfaction of patients, a total of five questions were asked in a survey as follows: (1) Satisfaction with postoperative nose shape (if unsatisfactory, what is the reason?); (2) Satisfaction with postoperative functional aspect (if unsatisfactory, what is the reason?); (3) Overall satisfaction with closed reduction; (4) If you were able to return to the preoperative state, would you choose to undergo the same surgery again?; and (5) Would you like to have revision through cosmetic surgery?

All questions were scored on a 5-point scale, with 5 points representing the highest satisfaction and positivity. Google survey (Google, Berkeley, CA, USA), a web-based survey program, was used for the survey. Only patients who consented to the survey verbally over the phone were sent a mobile message containing the purpose of the study and a link to the survey. All patients anonymously accessed the survey link and participated in the survey voluntarily. Of a total of 211 patients, eight patients (25.8\%) in the Am group, 13 patients (22.4\%) in the As group, seven patients (35\%) in the Bm group, 24 patients (32\%) in the Bs group, and nine patients (33.3\%) in the C group participated in the survey. The numbers in parentheses indicate the response rate in each group. A total of 61 patients $(28.9 \%)$ participated in the survey (Fig. 2).

\section{Statistical analysis}

For comparisons of aesthetic satisfaction, functional satisfaction, and satisfaction with closed reduction depending on fracture type, the Kruskal-Wallis test, a nonparametric test, was applied because the five participant groups failed to meet normality in the Shapiro-Wilk test of normality.

To compare aesthetic satisfaction, functional satisfaction, and satisfaction of closed reduction depending on fracture site, patients were divided into three groups including a unilateral group $(\mathrm{Am}+\mathrm{As})$, a bilateral group $(\mathrm{Bm}+\mathrm{Bs})$, and a comminuted group $(\mathrm{C})$. Since they failed to meet normality in the ShapiroWilk test of normality, the Kruskal-Wallis test was used for comparison.

In addition, patients were classified into a mild group (Am+ $\mathrm{Bm}$ ), a severe group (As+Bs), and a comminuted group (C) in order to compare aesthetic satisfaction, functional satisfaction, and satisfaction with closed reduction depending on fracture severity. Since they did not meet normality in the Shapiro-Wilk test of normality, the Kruskal-Wallis test was used for comparison.

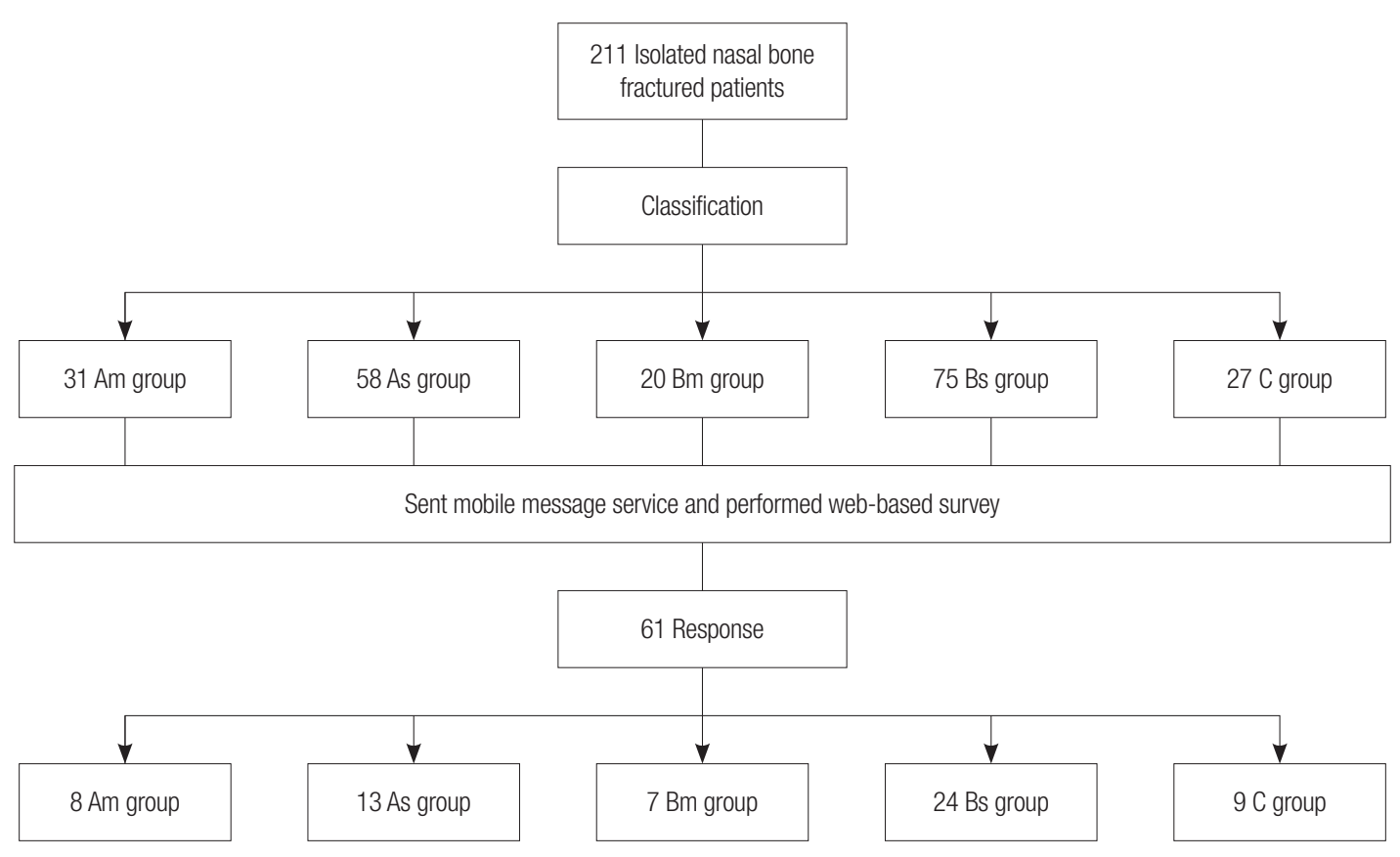

Fig. 2. Study group selection flowchart. Am, unilateral fracture without septal fracture or prominent septal deviation; As, unilateral fracture with septal fracture or prominent septal deviation; Bm, bilateral fracture without septal fracture or prominent septal deviation; Bs, bilateral fracture with septal fracture or prominent septal deviation; C, comminuted fracture. 
For the comparison of aesthetic complications and functional complications depending on fracture type, a complication was scored 1 point, while no complication was scored 0 . The Kruskal-Wallis test was used for comparison because they failed to meet normality in the Shapiro-Wilk test of normality. All statistical analyses were performed using SPSS version 23.0 (IBM Corp., Armonk, NY, USA). Statistical significance was defined when a $p$-value was less than 0.05 .

\section{RESULTS}

\section{Demographics}

Of the 211 patients who received closed reduction for isolated nasal bone fracture from January 2017 to December 2018, the Bs group with 75 patients (35.5\%) had the highest number of patients, followed by the As group with 58 patients (27.5\%), the Am group with 31 patients (14.7\%), the C group with 27 patients (12.8\%), and the Bm group with 20 patients (9.5\%).
There were 157 males and 54 females. Relatively severe fracture types had a higher male to female ratio. The highest mean age was found in the C group (43.37 years), followed by the Bs group (33.89 years), the As group (34.76 years), the Bm group (28.00 years), and the Am group (24.55 years). The mean age of the total patient group was 33.41 years. The average time from injury to closed reduction surgery was 5.5 days (Table 1 ).

The most common cause of nasal bone fracture was falling down, followed by assault, traffic accident, sports injury, and work place injury. In all the groups, falling down was the most common cause. On the other hand, traffic accidents were the second most common cause in the Bs and $\mathrm{C}$ groups, whereas assaults were the second most common cause in the Am and As groups (Fig. 3).

\section{Satisfaction according to fracture type}

The overall mean score for aesthetic satisfaction depending on fracture type was 3.80 points, showing scores in the following

Table 1. Demographic characteristics of patients with total nasal bone fracture

\begin{tabular}{|c|c|c|c|c|c|c|}
\hline Characteristic & $\mathrm{Am}$ & As & $\mathrm{Bm}$ & Bs & C & Total \\
\hline \multicolumn{7}{|l|}{ Sex } \\
\hline Male & 18 & 42 & 14 & 62 & 21 & 157 \\
\hline Female & 13 & 16 & 6 & 13 & 6 & 54 \\
\hline Male/female ratio & 1.38 & 2.63 & 2.33 & 4.77 & 3.50 & 2.93 \\
\hline Total, no. (\%) & $31(14.69)$ & $58(27.49)$ & $20(9.48)$ & 75 (35.56) & 27 (12.79) & $211(100)$ \\
\hline $\operatorname{Age}(y r)^{a)}$ & 24.55 & 34.76 & 28.00 & 33.89 & 43.37 & 33.41 \\
\hline Injury to operation (day) & 5.7 & 5.7 & 4.8 & 5.4 & 5.7 & 5.5 \\
\hline
\end{tabular}

Am, unilateral fracture without septal fracture or prominent septal deviation; As, unilateral fracture with septal fracture or prominent septal deviation; Bm, bilateral fracture without septal fracture or prominent septal deviation; Bs, bilateral fracture with septal fracture or prominent septal deviation; C, comminuted fracture.

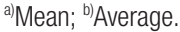
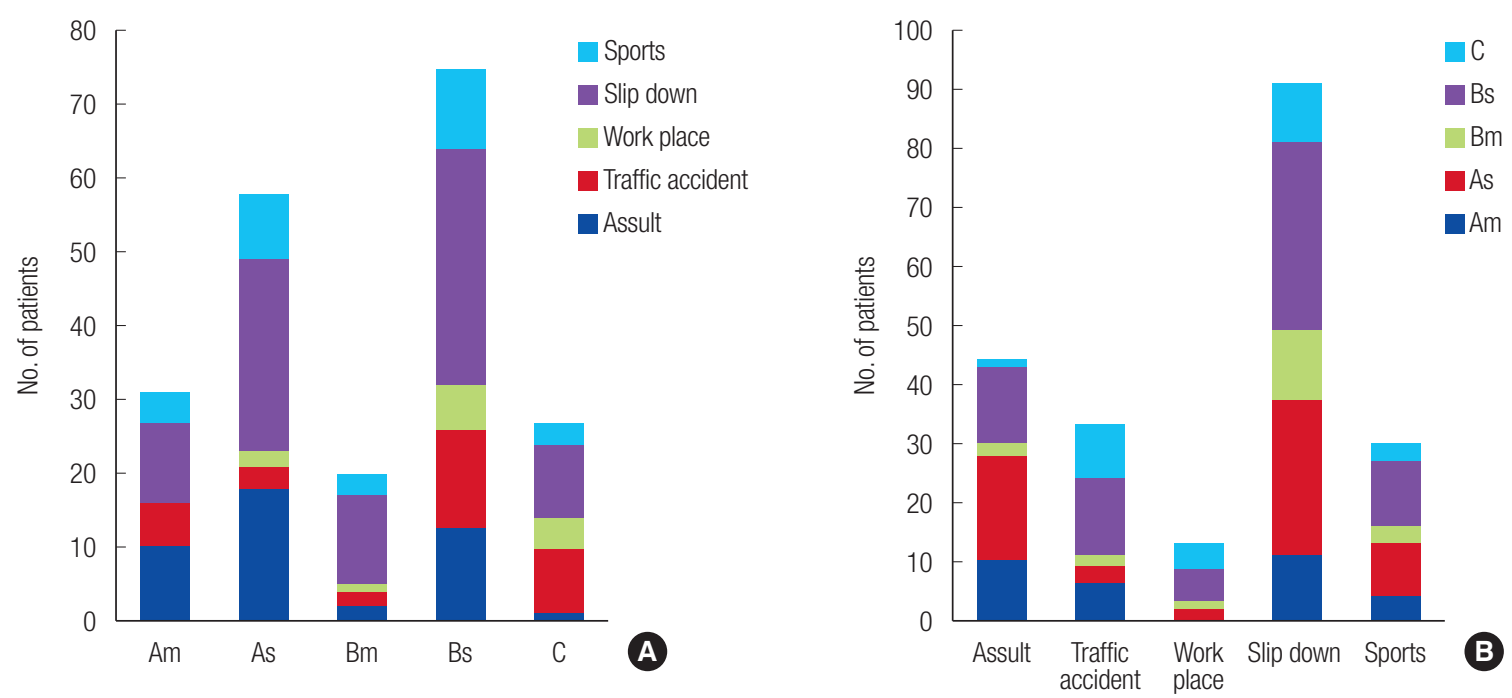

Fig. 3. (A, B) Injury type of nasal bone fracture according to fracture type. Am, unilateral fracture without septal fracture or prominent septal deviation; As, unilateral fracture with septal fracture or prominent septal deviation; Bm, bilateral fracture without septal fracture or prominent septal deviation; Bs, bilateral fracture with septal fracture or prominent septal deviation; C, comminuted fracture. 
order (from the highest to the lowest): C, Bm, As, Am, and Bs. However, there were no statistically significant differences. The overall mean score for functional satisfaction depending on fracture type was 3.97 points, showing scores in the following order (from the highest to the lowest): C, Bm, Am, As, and Bs. However, there were no statistically significant differences. Regarding fracture type, the total mean score for closed reduction satisfaction was 4.01, showing scores in the following order (from the highest to the lowest): Bm, C, As, Bs, and Am. However, there were no statistically significant differences (Table 2).

\section{Satisfaction according to fracture site}

Aesthetic satisfaction scores according to fracture site were the highest in the comminuted group, followed by the bilateral group, and then the unilateral group. However, there were no statistically significant differences. Functional satisfaction scores according to fracture site were the highest in the comminuted group, followed by the unilateral group, and then the bilateral group. However, there were no statistically significant

Table 2. Satisfaction score according to the fracture type

\begin{tabular}{|c|c|c|c|c|c|}
\hline Fracture type & $\begin{array}{c}\text { No. of } \\
\text { patients }\end{array}$ & $\begin{array}{l}\text { Satisfaction } \\
\text { score }\end{array}$ & $\chi^{2}$ & $\mathrm{df}$ & $p$-value ${ }^{\text {a) }}$ \\
\hline Aesthetic satisfaction & & & 4.766 & 4 & 0.312 \\
\hline Am & 8 & $3.63 \pm 1.30$ & & & \\
\hline As & 13 & $3.69 \pm 1.11$ & & & \\
\hline $\mathrm{Bm}$ & 7 & $4.29 \pm 0.75$ & & & \\
\hline Bs & 24 & $3.58 \pm 1.10$ & & & \\
\hline C & 9 & $4.33 \pm 0.86$ & & & \\
\hline Total & 61 & $3.80 \pm 1.08$ & & & \\
\hline Functional satisfaction & & & 6.797 & 4 & 0.147 \\
\hline Am & 8 & $4.13 \pm 1.36$ & & & \\
\hline As & 13 & $3.92 \pm 1.32$ & & & \\
\hline $\mathrm{Bm}$ & 7 & $4.43 \pm 0.78$ & & & \\
\hline Bs & 24 & $3.58 \pm 1.10$ & & & \\
\hline C & 9 & $4.55 \pm 0.52$ & & & \\
\hline Total & 61 & $3.97 \pm 1.12$ & & & \\
\hline Closed reduction satisfaction & & & 5.941 & 4 & 0.204 \\
\hline Am & 8 & $3.63 \pm 1.19$ & & & \\
\hline As & 13 & $4.15 \pm 0.98$ & & & \\
\hline $\mathrm{Bm}$ & 7 & $4.57 \pm 0.53$ & & & \\
\hline Bs & 24 & $3.79 \pm 0.93$ & & & \\
\hline C & 9 & $4.33 \pm 0.86$ & & & \\
\hline Total & 61 & $4.01 \pm 0.96$ & & & \\
\hline
\end{tabular}

Values are presented as mean \pm standard deviation.

Am, unilateral fracture without septal fracture or prominent septal deviation; As, unilateral fracture with septal fracture or prominent septal deviation; Bm, bilateral fracture without septal fracture or prominent septal deviation; Bs, bilateral fracture with septal fracture or prominent septal deviation; C, comminuted fracture.

a)Kruskal-Wallis test differences. Scores for closed reduction satisfaction according to fracture site were the highest in the comminuted group, followed by the bilateral group, and then the unilateral groups. However, there were no statistically significant differences (Table 3$)$.

\section{Satisfaction according to fracture severity}

Aesthetic satisfaction scores according to fracture severity were the highest in the comminuted group, followed by the mild group, and then the severe group. However, there were no statistically significant differences. Functional satisfaction scores according to fracture severity were the highest in the comminuted group, followed by the mild group, and then the severe group. However, there were no statistically significant differences. Closed reduction satisfaction scores according to fracture severity were the highest in the comminuted group, followed by the mild group, and then the severe group. However, there were no statistically significant differences (Table 4).

\section{Postoperative complications according to fracture type}

A total of 14 patients (22.95\%) had postoperative aesthetic complications, including deviated nose in 12 patients (19.97\%), hump nose in one patient (1.64\%), and saddle nose in one patient (1.64\%). As for aesthetic complications by fracture type, there were six patients in the Bs group, four patients in the As

Table 3. Satisfaction score according to the fracture site

\begin{tabular}{lrcrrr}
\hline Fracture site & $\begin{array}{c}\text { No. of } \\
\text { patients }\end{array}$ & $\begin{array}{c}\text { Satisfaction } \\
\text { score }\end{array}$ & $\chi^{2}$ & df & p-value a $^{\text {a) }}$ \\
\hline Aesthetic satisfaction & & & 2.535 & 2 & 0.282 \\
Unilateral (Am+As) & 20 & $3.67 \pm 1.15$ & & & \\
Bilateral (Bm+Bs) & 30 & $3.74 \pm 1.06$ & & \\
Comminuted (C) & 9 & $4.33 \pm 0.86$ & & & \\
Total & 61 & $3.80 \pm 1.08$ & & & \\
Functional satisfaction & & & 2.956 & 2 & 0.228 \\
Unilateral (Am+As) & 20 & $4.00 \pm 1.30$ & & & \\
Bilateral (Bm+Bs) & 32 & $3.77 \pm 1.09$ & & & \\
Comminuted (C) & 9 & $4.55 \pm 0.52$ & & & \\
Total & 61 & $3.97 \pm 1.12$ & & & \\
Closed reduction satisfaction & & & & & \\
Unilateral (Am+As) & 20 & $3.95 \pm 1.07$ & & & \\
Bilateral (Bm+Bs) & 32 & $3.96 \pm 0.91$ & & \\
Comminuted (C) & 9 & $4.33 \pm 0.86$ & & & \\
Total & 61 & $4.01 \pm 0.96$ & & & \\
\hline
\end{tabular}

Values are presented as mean \pm standard deviation.

Am, unilateral fracture without septal fracture or prominent septal deviation; As, unilateral fracture with septal fracture or prominent septal deviation; Bm, bilateral fracture without septal fracture or prominent septal deviation; Bs, bilateral fracture with septal fracture or prominent septal deviation; C, comminuted fracture.

a)Kruskal-Wallis test. 
group, three patients in the Am group, and one patient in the $\mathrm{C}$ group, whilst there were no aesthetic complications in the $\mathrm{Bm}$ group. The highest aesthetic complication rate (\%) was found in the Am group (33.33\%), followed by the As (30.77\%), Bs (25.00\%), C (11.11\%), and Bm (0\%) groups. However, there were no statistically significant differences. Postoperative functional complications were found in a total of 14 patients $(22.95 \%)$, including seven patients (11.47\%) with nasal obstruction, three patients $(4.92 \%)$ with rhinorrhea, two patients $(3.28 \%)$ with pain, and two patients (3.28\%) with nasal bleeding. As for functional complications according to fracture type, there were 10 patients in the Bs group, two patients in the As group, and two

Table 4. Satisfaction score according to the fracture severity

\begin{tabular}{lrcccc}
\hline Severity & $\begin{array}{c}\text { No. of } \\
\text { patients }\end{array}$ & $\begin{array}{c}\text { Satisfaction } \\
\text { score }\end{array}$ & $\chi^{2}$ & df & $p$-value \\
\hline Aesthetic satisfaction & & & 3.449 & 2 & 0.178 \\
$\quad$ Mild (Am+Bm) & 15 & $3.93 \pm 1.09$ & & & \\
Severe (As+Bs) & 37 & $3.62 \pm 1.09$ & & & \\
Comminuted (C) & 9 & $4.33 \pm 0.86$ & & & \\
Total & 61 & $3.80 \pm 1.08$ & & & 0.070 \\
Functional satisfaction & & & 5.310 & 2 & \\
Mild (Am+Bm) & 15 & $4.26 \pm 1.09$ & & & \\
Severe (As+Bs) & 37 & $3.70 \pm 1.17$ & & & \\
Comminuted (C) & 9 & $4.55 \pm 0.52$ & & & \\
Total & 61 & $3.97 \pm 1.12$ & & & \\
Closed reduction satisfaction & & & 1.517 & 2 & 0.468 \\
Mild (Am+Bm) & 15 & $4.07 \pm 1.32$ & & & \\
Severe (As+Bs) & 37 & $3.92 \pm 0.95$ & & & \\
Comminuted (C) & 9 & $4.33 \pm 0.86$ & & \\
Total & 61 & $4.01 \pm 0.96$ & &
\end{tabular}

Values are presented as mean \pm standard deviation.

Am, unilateral fracture without septal fracture or prominent septal deviation; As, unilateral fracture with septal fracture or prominent septal deviation; Bm, bilateral fracture without septal fracture or prominent septal deviation; Bs, bilateral fracture with septal fracture or prominent septal deviation; C, comminuted fracture.

a)Kruskal-Wallis test patients in the Am group, whilst there were no functional complications in the $\mathrm{C}$ and $\mathrm{Bm}$ groups. The highest functional complication rate (\%) was found in the Bs (41.67\%) group, followed by the Am (25.00\%), As (15.38\%), C (0\%), and Bm (0\%) groups. Postoperative functional complications were significantly different according to fracture type $(p=0.044)$ (Tables 5 and 6, Fig. 4).

\section{Operative intention according to fracture type}

When patients were asked if they would choose closed reduction again if they had the same nasal bone fracture injury, the overall score for intention to choose closed reduction again was 3.70 on average, with the highest scores in the Bm group, followed by the C, As, Am, and Bs groups. However, there were no statistically significant differences. The overall mean score for intention to choose rhinoplasty due to the current nasal condition after closed reduction of nasal bone fracture was 3.03 points, with the highest scores in the Am group, followed by the $\mathrm{Bm}, \mathrm{C}, \mathrm{Bs}$, and As groups. However, there were no statistically significant differences (Table 7).

Table 5. Aesthetic complication rate according to the fracture type

\begin{tabular}{|c|c|c|c|c|c|c|}
\hline \multirow{2}{*}{$\begin{array}{l}\text { Fracture } \\
\text { type }\end{array}$} & \multirow{2}{*}{$\begin{array}{l}\text { No. of } \\
\text { patients }\end{array}$} & \multicolumn{3}{|c|}{ Complication type } & \multirow[b]{2}{*}{ Total (\%) } & \multirow{2}{*}{$p$-value $\mathrm{a}^{\mathrm{a}}$} \\
\hline & & $\begin{array}{l}\text { Deviated } \\
\text { nose }\end{array}$ & Hump nose & $\begin{array}{l}\text { Saddle } \\
\text { nose }\end{array}$ & & \\
\hline Am & 8 & 3 & 0 & 0 & 3 (33.33) & \\
\hline As & 13 & 3 & 1 & 0 & $4(30.77)$ & \\
\hline $\mathrm{Bm}$ & 7 & 0 & 0 & 0 & 0 & \\
\hline Bs & 24 & 5 & 0 & 1 & $6(25.00)$ & \\
\hline C & 9 & 1 & 0 & 0 & $1(11.11)$ & \\
\hline Total (\%) & $61(100)$ & 12 (19.67) & $1(1.64)$ & $1(1.64)$ & 14 (22.95) & 0.381 \\
\hline
\end{tabular}

Values are presented as number or number (\%).

Am, unilateral fracture without septal fracture or prominent septal deviation; As, unilateral fracture with septal fracture or prominent septal deviation; Bm, bilateral fracture without septal fracture or prominent septal deviation; Bs, bilateral fracture with septal fracture or prominent septal deviation; C, comminuted fracture.

a)Kruskal-Wallis test.

Table 6. Functional complication rate according to the fracture type

\begin{tabular}{|c|c|c|c|c|c|c|c|}
\hline \multirow{2}{*}{ Fracture type } & \multirow{2}{*}{ No. of patients } & \multicolumn{4}{|c|}{ Complication type } & \multirow{2}{*}{ Total (\%) } & \multirow{2}{*}{$p$-value ${ }^{a}$} \\
\hline & & Pain & Nasal obstruction & Nasal bleeding & Rhinorrhea & & \\
\hline Am & 8 & 2 & 0 & 0 & 0 & $2(25.00)$ & \\
\hline As & 13 & 0 & 2 & 0 & 0 & 2 (15.38) & \\
\hline $\mathrm{Bm}$ & 7 & 0 & 0 & 0 & 0 & 0 & \\
\hline Bs & 24 & 0 & 5 & 2 & 3 & $10(41.67)$ & \\
\hline C & 9 & 0 & 0 & 0 & 0 & 0 & \\
\hline Total & $61(100)$ & $2(3.28)$ & $7(11.47)$ & $2(3.28)$ & $3(4.92)$ & $14(22.95)$ & $0.044^{b)}$ \\
\hline
\end{tabular}

Values are presented as number or number (\%).

Am, unilateral fracture without septal fracture or prominent septal deviation; As, unilateral fracture with septal fracture or prominent septal deviation; Bm, bilateral fracture without septal fracture or prominent septal deviation; Bs, bilateral fracture with septal fracture or prominent septal deviation; C, comminuted fracture.

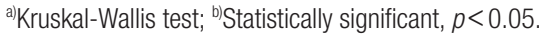



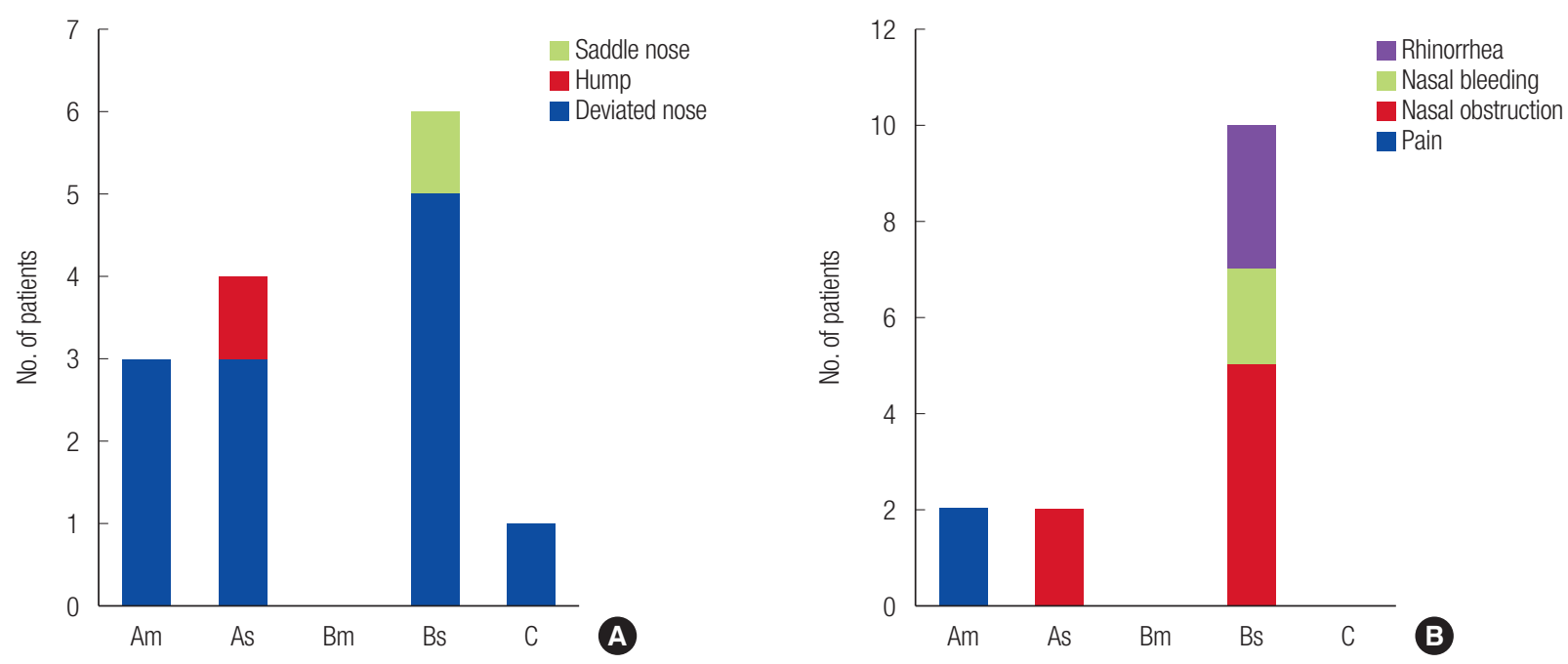

Fig. 4. (A) Aesthetic complication rate according to fracture type. (B) Functional complication rate according to fracture type. Am, unilateral fracture without septal fracture or prominent septal deviation; As, unilateral fracture with septal fracture or prominent septal deviation; Bm, bilateral fracture without septal fracture or prominent septal deviation; Bs, bilateral fracture with septal fracture or prominent septal deviation; $\mathrm{C}$, comminuted fracture.

Table 7. Intension score according to the fracture type

\begin{tabular}{lccccc}
\hline Fracture type & $\begin{array}{c}\text { No. of } \\
\text { patients }\end{array}$ & $\begin{array}{c}\text { Intension } \\
\text { score }\end{array}$ & $\chi^{2}$ & df & $p$-value \\
\hline Closed reduction & & & 6.644 & 4 & 0.156 \\
Am & 8 & $3.50 \pm 1.51$ & & & \\
As & 13 & $4.00 \pm 1.22$ & & & \\
Bm & 7 & $4.57 \pm 0.78$ & & & \\
Bs & 24 & $3.25 \pm 1.48$ & & & \\
C & 9 & $4.00 \pm 1.41$ & & & \\
Total & 61 & $3.70 \pm 1.39$ & & & \\
Rhinoplasty & & & 2.392 & 4 & 0.664 \\
Am & 8 & $3.50 \pm 1.69$ & & & \\
As & 13 & $2.77 \pm 1.42$ & & & \\
Bm & 7 & $3.42 \pm 1.81$ & & & \\
Bs & 24 & $2.87 \pm 1.29$ & & & \\
C & 9 & $3.11 \pm 1.61$ & & & \\
Total & 61 & $3.03 \pm 1.46$ & & & \\
\hline
\end{tabular}

Values are presented as mean \pm standard deviation.

Am, unilateral fracture without septal fracture or prominent septal deviation; As, unilateral fracture with septal fracture or prominent septal deviation; Bm, bilateral fracture without septal fracture or prominent septal deviation; Bs, bilateral fracture with septal fracture or prominent septal deviation; $\mathrm{C}$, comminuted fracture.

a)Kruskal-Wallis test.

\section{DISCUSSION}

The nose is a protruding organ at the center of the face and an opening of the respiratory system. Nasal bone fracture is common and may result in aesthetic disapproval and functional disorders. Therefore, it is imperative to evaluate satisfaction and complications in patients postoperatively to establish additional treatment options for potential deformities and functional issues that may occur following surgery. Hence, there are various studies on patient satisfaction and postoperative complications after closed reduction of nasal bone fractures $[9,12,13]$. However, satisfaction is a highly subjective evaluation, and factors affecting satisfaction [8] are diverse, including the postoperative follow-up period, reduction time, and fracture severity, all of which limit the evaluation of prognosis and complications [79]. Thus, the present study aimed to evaluate and predict the prognosis of patients through scoring and comparison of longterm satisfaction, complications, and revision intention after closed reduction according to various factors.

In the present study, the $\mathrm{C}$ and $\mathrm{Bm}$ groups showed higher scores for aesthetic and functional satisfaction, as well as closed reduction satisfaction, compared to the As and Bs groups; however, these differences were not statistically significant. Similarly, Kang and Han $[9,14]$ also reported no statistically significant differences according to fracture type, although the classification of fracture types was different from that in the present study.

On the other hand, regarding satisfaction according to fracture severity, Yilmaz et al. [8] reported that the mild type fracture group showed relatively better satisfaction. In contrast, the present study showed higher aesthetic and functional satisfaction scores, as well as closed reduction satisfaction scores in the comminuted group, compared to the mild and severe groups. Whilst these differences were not statistically significant, these results were different from those of the previous study.

Scores for intention to reselect closed reduction, according to fracture type, showed a similar pattern. This indicates that the 
patient's choice whether they would opt for closed reduction again, was dependent on their satisfaction. Nineteen patients out of a total of 61 (for 31.15\%) wanted postoperative rhinoplasty (a score of 4 or 5 points). The rhinoplasty intention score by type was relatively higher in mild types, such as the Am and Bm groups, although there were no significant differences. This is consistent with the results of Hung et al. [7] that showed that postoperative satisfaction and revision surgery would be inconsistent.

In our study, unilateral groups, such as the Am and As groups, showed a relatively higher aesthetic complication rate within the group after closed reduction, although there were no statistically significant differences. On the other hand, the Bs group showed the highest functional complication rate (41.6\%), which was statistically significant $(p=0.044)$. Consistent with our findings, Kang and Han $[9,14]$ reported significant differences in complications within the patients with septal deviation, although the fracture classification was different from that in our study. In particular, the present study found that the As and Bs groups included many septum deviations and the fractures had a higher rate of nasal obstruction.

In comparison to previous studies, the present study was able to compare relatively long-term satisfaction and complications after closed reduction because we targeted long-term patients. In addition, we believe that this study offers a more honest and subjective evaluation because it employed a web-based survey instead of a face-to-face interview with an operator. However, the response rate was only about $30 \%$ of the study population, providing a relatively small sample size for evaluation. Furthermore, the web-based survey evaluation method may have resulted in an age bias.

In conclusion, patients with isolated nasal bone fracture can be classified into various groups depending on fracture type. And The incidence of complications is higher for bilateral fracture with septal fracture or prominent septal deviation compared to the other nasal bone fracture types. Therefore, longterm follow-up after closed reduction surgery for this fracture type can aid in establishing additional postoperative treatment plans and improving patient satisfaction.

\section{NOTES}

\section{Conflict of interest}

No potential conflict of interest relevant to this article was reported.

\section{Ethical approval}

The study was approved by the Institutional Review Board of
Chosun University Hospital (IRB No. 2019-09-004-002) and performed in accordance with the principles of the Declaration of Helsinki. The informed consent was waived.

\section{ORCID}

Min Hyub Choi https://orcid.org/0000-0002-6844-0526

Ji Seon Cheon https://orcid.org/0000-0001-8555-5088

Kyung Min Son https://orcid.org/0000-0001-5825-0270

Woo Young Choi https://orcid.org/0000-0001-8849-1569

\section{REFERENCES}

1. Rhee SC, Kim YK, Cha JH, Kang SR, Park HS. Septal fracture in simple nasal bone fracture. Plast Reconstr Surg 2004;113:45-52.

2. Farber SJ, Nguyen DC, Parikh RP, Jang JL, Woo AS. Improving results in closed nasal reduction: a protocol for reducing secondary deformity. Plast Reconstr Surg 2017;139:51-9.

3. Rohrich RJ, Adams WP Jr. Nasal fracture management: minimizing secondary nasal deformities. Plast Reconstr Surg 2000; 106:266-73.

4. Murray JA, Maran AG. The treatment of nasal injuries by manipulation. J Laryngol Otol 1980;94:1405-10.

5. Sam A, Deshmukh PT, Patil C, Jain S, Patil R. Nasal septal deviation and external nasal deformity: a correlative study of 100 cases. Indian J Otolaryngol Head Neck Surg 2012;64:312-8.

6. Oh HK, Park YJ, Kim HS, Ryu JY, Kook MS, Park HJ, et al. A recent 5-year retrospective study on nasal bone fracture. J Korean Assoc Oral Maxillofac Surg 2008;34:230-6.

7. Hung T, Chang W, Vlantis AC, Tong MC, van Hasselt CA. Patient satisfaction after closed reduction of nasal fractures. Arch Facial Plast Surg 2007;9:40-3.

8. Yilmaz MS, Guven M, Varli AF. Nasal fractures: is closed reduction satisfying? J Craniofac Surg 2013;24:e36-8.

9. Kang CM, Han DG. Correlation between operation result and patient satisfaction of nasal bone fracture. Arch Craniofac Surg 2017;18:25-9.

10. Murray JA, Maran AG, Busuttil A, Vaughan G. A pathological classification of nasal fractures. Injury 1986;17:338-44.

11. Higuera S, Lee EI, Cole P, Hollier LH Jr, Stal S. Nasal trauma and the deviated nose. Plast Reconstr Surg 2007;120:64S-75S.

12. Staffel JG. Optimizing treatment of nasal fractures. Laryngoscope 2002;112:1709-19.

13. Ridder GJ, Boedeker CC, Fradis M, Schipper J. Technique and timing for closed reduction of isolated nasal fractures: a retrospective study. Ear Nose Throat J 2002;81:49-54.

14. Kang CM, Han DG. Objective outcomes of closed reduction according to the type of nasal bone fracture. Arch Craniofac Surg 2017;18:30-6. 